\title{
Analysis of the rainfall influence on critical wind speed of flutter of long-span suspension bridge based on mumerical method
}

\author{
Hu Jun* \\ School of Civil Engineering, Chongqing Jiao tong University, Chongqing 400074, China
}

\begin{abstract}
In order to study the influence of rainfall on the critical wind speed of flutter of long-span suspension bridges in mountainous area, the impact of rainfall on stiffening girder is analyzed based on the main characteristics of rainfall and the movement speed in all directions. The mechanical equation under the joint action of wind and rain is established and the impact force is transferred, the damping effect of rainfall is then derived, and the element damping matrix form of rainfall is obtained by combining the integration of shape function. Furthermore, the flutter motion equation of wind-rain-bridge coupling system is derived, and the finite element analysis method for critical wind speed of structural flutter considering the influence of rainfall is established. Finally, taking a large-span suspension bridge in mountainous area as the research object, the influence of rainfall on the critical wind speed of flutter is analyzed, the results indicate that the critical wind speed of flutter will be accordingly increased due to the existence of rainfall damping, whereas the mass of raindrops is too light and the final velocity of raindrops in the falling process is low, the critical wind speed of flutter increased by only $5.54 \%$ in the case of heavy rainstorm. Therefore, when the rainfall intensity is general, the influence of rainfall on the critical wind speed of flutter can be ignored.
\end{abstract}

\section{Introduction}

With the continuously increase of bridge span, the structure tends to be flexible and the damping reduces correspondingly, long-span suspension bridges are sensitive to the wind which can generate some vibrations including flutter, galloping, buffeting and vortex-induced oscillation[1], so the wind resistance safety of the main beam has become an important factor in the design of the long-span suspension bridge[2]. The wind-induced flutter instability of the Tacoma Narrow Bridge in 1940 initiated the study on the wind resistance of bridges. Bridge flutter is a very dangerous self-induced divergent vibration induced by the wind, and the force causing flutter is a kind of unsteady aerodynamic self-excited force that the wind interacts with the long-span flexible bridge [3]. Severe convective weather often occurs in the process of flutter, and it is often accompanied by heavy rainfall. Although the flutter phenomenon of long-span bridges has been studied by researchers at domestic and foreign[4], there are few studies on the effect of rainfall on the critical wind speed of flutter.
Lei Xu et al.[5] conducted wind tunnel test with wind and rain coupling and found the total damping ratio of the structure increases under the condition of rainfall, which is conducive to the reduction of vortex-vibration response, whereas the effect on the stability of flutter is small and can be ignored. Wang Liang[6] found that the aerodynamic derivatives were greatly affected by rainfall, and the critical wind speed of flutter at the positive attack angle was smaller than that at the negative attack angle based on the study on the stability of flutter induced by wind and rain of long-span bridges. Zhao Lin et al.[7] conducted related research on the structural load and response under the combined action of wind and rain using theoretical analysis and experimental research methods, and the results indicate that rainfall has a certain influence on the steady aerodynamic force of the model, while the change of rain intensity has little influence on the force acting on the model. Fu Xing[8] proposed a simplified method to calculate wind and rain load by using equivalent basic wind speed, it can effectively avoid the problem of combination of basic wind speed and rainfall intensity when the equivalent basic wind speed is used for damage analysis. Cao et al.[9] explored the additional effects of heavy rainfall on aircraft before 
landing based on the theoretical analysis, numerical simulation and wind tunnel tests, and pointed out that rainfall can significantly reduce the lift of aircraft and increase its resistance. Dong Guochao et al.[10] studied the influence of wind-rain coupling on the static three-component force coefficient of a typical bridge section and the mechanism of three-dimensional wind-rain coupling on a typical bridge section, providing a theoretical basis for the study of wind-rain coupling load. Gao Q[11] proposed a one-way coupling analysis method for the three fields of wind-rain structure under the simultaneous action of wind and rain, the CFD software was used to simulate the process of rain driven by wind, and the impact of wind pressure and raindrops on the wind turbine was obtained. Masaru Abuku[12] implemented relevant research on the impact of raindrops driven by wind on the structure through numerical simulation and experiments, and the research showed that raindrops had more effect on the upper part of the structure than on the lower part.

Based on the analysis of the main characteristics of rainfall, the rainfall damping is proposed combined with the impact of rainfall on bridge deck in this paper, the flutter motion equation is generated for the wind-rain-bridge coupling system and the solution method for the critical wind speed of flutter is given. Finally, taking a long span suspension bridge in Hubei China as an engineering example, the influence of rainfall on critical wind speed of bridge flutter is studied.

\section{Analysis method of bridge flutter under coupling of wind and rain}

\subsection{The basic assumptions}

The causes of flutter of long-span bridges under the effect of wind and rain coupling are very complicated, the following hypotheses are proposed in this paper based on the characteristics and action principle of wind and rain:

(1)Only the average wind in the wind field of the bridge site is taken into account, the fluctuating wind component is ignored, and the rainfall will not change the wind characteristics.

(2)The shape of raindrops in falling process is regarded as small ball, and its physical parameters will not change in the process of movement.

(3)When raindrops strike the surface of the bridge structure, the effect of raindrops is continuous and uniform.

(4)When the raindrops fall and collide with the surface of the structure, all the water droplets are attached to the surface of the structure, meanwhile, ignoring the possible secondary effects on the structures caused by raindrops splash and bounce.

(5)In the process of raindrops falling, the gravity of the raindrops is equal to the air resistance and is in the opposite direction, so the falling speed is considered to be uniform. Based on the related research conducted by Masaru Abuku et al.[12], in the along-wind direction, it is assumed that the rainfall speed is 1.7 times of the average wind speed, in the vertical direction, the free falling speed of raindrops is assumed to be $\mathrm{Vm}$.

(6)In the analysis of wind field, the wind load of the bridges is mainly borne by the stiffening girder, and the influence of rainfall on the three-component force coefficient and aerodynamic derivatives of the stiffening girder is ignored.

\subsection{Analysis model of bridge flutter}

Based on the above assumptions, the flutter effect of bridge structure under the action effect of wind and rain coupling is studied. Wind load is mainly borne by the stiffening girder of suspension bridge, so only the influence of wind and rain on the stiffening girder is explored in this paper, as shown in Fig.1. 


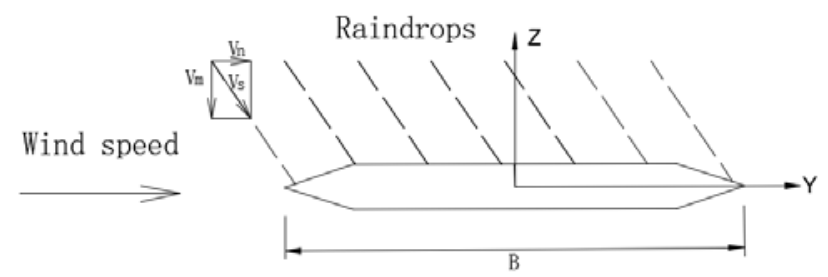

Fig.1 The combined action of wind and rain on the stiffening beam

The impact of raindrops on bridge deck is a process of momentum change, the motion of the stiffening girder is also considered, the impact force of each raindrops will be calculated by Formula (1), namely:

$$
F_{0}^{\prime}(\tau)=\frac{m_{0}\left(V_{s}-V\right)}{\tau}
$$

where $F_{0}^{\prime}(\tau)$ is the impact of each raindrops on the stiffening girder; $m_{0}$ is the mass of each raindrops; $\tau$ is the duration of the raindrops impact process, $\tau=\frac{2 d_{0}}{\pi\left(V_{s}-V\right)} ; \quad V_{s}$ is the falling speed of raindrops

$V$ is the structural motion velocity at which raindrops collide.

It is assumed that the impact of raindrops on the structure is continuous and uniform, then the surface load of rainfall is obtained by $f=\alpha F_{0}(\tau) / A, \alpha$ is the volume occupation rate of raindrops in the air, $A_{\text {is }}$ the action area of raindrops, $\alpha=\frac{1}{6} \pi d_{0}^{3} n_{0}$ and $A=\frac{1}{4} \pi d_{0}^{2} \quad$ are taken respectively.

It is assumed that the section of the stiffening girder moves along the $\mathrm{Y}$ axis and $\mathrm{Z}$ axis in Fig.1 respectively and torsional movement is carried out at speed $\theta \mathrm{x}$, the rainfall impact load of cross section can be obtained by integrating the surface load of rainfall, as shown in Formula (2),

$F_{Y}=\frac{1}{18} \rho \pi^{2} B n_{0} d_{0}^{3}\left(V_{n}-\dot{Y}\right)^{2}$

$$
\begin{aligned}
& F_{Z}=-\frac{1}{18} \rho \pi^{2} B n_{0} d_{0}^{3}\left(V_{m}+\dot{Z}\right)^{2} \\
& M_{X}=-\frac{1}{108} \rho \pi^{2} n_{0} d_{0}^{3} B^{3} V_{m} \dot{\theta}_{x}
\end{aligned}
$$

where $\dot{Y} 、 \dot{Z}$ and $\dot{\theta}_{x}$ are transverse, vertical and torsional motion velocities of cross section respectively; $\rho$ is the density of raindrops; $n_{0}$ and $d_{0}$ are the quantity and diameter of raindrops per unit volume in the process of rainfall respectively, whose value is related to rainfall; $B$ is the width of cross section; $\mathrm{Vm}$ is the terminal velocity of raindrops.

Gong Li [13] summarized the final velocity Vm of raindrops by studying a large number of literature and measured data, and calculated by Formula (3), namely:

$$
V_{m}=10^{6}\left(\frac{0.787}{d_{0}^{2}}+\frac{503}{\sqrt{d_{0}}}\right)^{-1}, d_{0}<1.0 \mathrm{~mm}
$$

$$
V_{m}=\left(17.2-0.844 d_{0}\right) \sqrt{d_{0}},\left(1.0<d_{0}<3.0 \mathrm{~mm}\right)
$$

$$
V_{m}=\frac{d_{0}}{0.113+0.845 d_{0}}, \quad\left(3.0<d_{0}<6.0 \mathrm{~mm}\right)
$$

Assigning the constant $\lambda$, namely: $\lambda=\frac{1}{18} \rho \pi^{2} B n_{0} d_{0}^{3}$, and it is assumed that the motion speed of cross section is far less than that of raindrops, and its square values $\dot{Y}^{2} 、 \dot{Z}^{2}$ and $\dot{\theta}_{x}{ }^{2}$ are ignored, when Formula (2) is expanded, the impact of rainfall is further 
expressed $\quad$ as $\quad F_{Y}=\lambda V_{n}^{2}-2 \lambda V_{n} \dot{Y} \quad$;

$$
F_{Z}=\lambda V_{m}^{2}-2 \lambda V_{m} \dot{Z} ; \quad M_{X}=-\frac{1}{6} \lambda B^{2} V_{m} \dot{\theta}_{x} .
$$

Therefore, the impact of rainfall can be decomposed into the impact force $\mathrm{P}$ and damping of rainfall $\mathrm{C}$, namely:

$$
\begin{aligned}
& P=\left(\lambda V_{n}^{2},-\lambda V_{m}^{2}, 0\right)^{T} \\
& C=\left(2 \lambda V_{n}, 2 \lambda V_{m}, \frac{\lambda B^{2} V_{m}}{6}\right)^{T} .
\end{aligned}
$$

and

. The impact of rainfall it has no influence on flutter analysis, so only the effect of rainfall damping is considered in flutter analysis. Based on the finite element theory, combined with the displacement interpolation function $N$ of spatial beam element and the principle of virtual work, the unit damping matrix of rainfall can be expressed as: $C_{R}=\int_{0}^{L} N^{T} C N d x$ , and the result after integration is shown in Formula (4).

only has a static displacement effect on the structures, and $C_{R}=\lambda L$.

$$
\left[\begin{array}{cccccccccccc}
0 & 0 & 0 & 0 & 0 & 0 & 0 & 0 & 0 & 0 & 0 & 0 \\
0 & \frac{26}{35} V_{n} & 0 & 0 & 0 & \frac{13}{210} L V_{n} & 0 & \frac{9}{35} V_{n} & 0 & 0 & 0 & -\frac{11}{105} L V_{n} \\
0 & 0 & \frac{26}{35} V_{m} & 0 & -\frac{13}{210} L V_{m} & 0 & 0 & 0 & \frac{9}{35} V_{m} & 0 & \frac{11}{105} L V_{m} & 0 \\
0 & 0 & 0 & \frac{1}{18} B^{2} V_{m} & 0 & 0 & 0 & 0 & 0 & \frac{1}{36} B^{2} V_{m} & 0 & 0 \\
0 & 0 & -\frac{13}{210} L V_{m} & 0 & \frac{2}{105} L^{2} V_{m} & 0 & 0 & 0 & -\frac{11}{105} L V_{m} & 0 & -\frac{1}{70} L^{2} V_{m} & 0 \\
0 & \frac{13}{210} L V_{n} & 0 & 0 & 0 & \frac{2}{105} L^{2} V_{n} & 0 & \frac{11}{105} L V_{n} & 0 & 0 & 0 & -\frac{1}{70} L^{2} V_{n} \\
0 & 0 & 0 & 0 & 0 & 0 & 0 & 0 & 0 & 0 & 0 & 0 \\
0 & \frac{9}{35} V_{n} & 0 & 0 & 0 & \frac{11}{105} L V_{n} & 0 & \frac{26}{35} V_{n} & 0 & 0 & 0 & -\frac{13}{210} L V_{n} \\
0 & 0 & \frac{9}{35} V_{m} & 0 & -\frac{11}{105} L V_{m} & 0 & 0 & 0 & \frac{26}{35} V_{m} & 0 & \frac{13}{210} L V_{m} & 0 \\
0 & 0 & 0 & \frac{1}{36} B^{2} V_{m} & 0 & 0 & 0 & 0 & 0 & \frac{1}{18} B^{2} V_{m} & 0 & 0 \\
0 & 0 & \frac{11}{105} L V_{m} & 0 & -\frac{1}{70} L^{2} V_{m} & 0 & 0 & 0 & \frac{13}{210} L V_{m} & 0 & \frac{2}{105} L^{2} V_{m} & 0 \\
0 & -\frac{11}{105} L V_{n} & 0 & 0 & 0 & -\frac{1}{70} L^{2} V_{n} & 0 & -\frac{13}{210} L V_{n} & 0 & 0 & 0 & \frac{2}{105} L^{2} V_{n}
\end{array}\right]
$$

It can be seen that if both the rainfall damping force $F_{R C}$ and the aerodynamic self-excited force $F_{s e}$ are taken into account, the following Formula(5) will be generated for the flutter analysis, namely:

$$
M \ddot{X}+C \dot{X}+K X=F_{s e}+F_{R C}
$$

where $F_{s e}$ is the aerodynamic expression of SCANLAN, when $F_{s e}$ acts on the stiffening girder of unit length, it can be decomposed into aerodynamic drag
$D_{s e}$, lift $L_{s e}$ and torque $M_{s e}$, corresponding to the displacement functions of horizontal direction torsion, vertical direction $h$ and torsion direction $\alpha$, respectively.

Therefore, the corresponding matrix of $F_{\text {se }}$ and $F_{R C}$ will be obtained respectively in the structural unit, and $F_{s e}$ includes two types of matrices, namely, aerodynamic stiffness and aerodynamic damping, 
represented by $K_{a e}$ and $C_{a e}$ respectively [14]. Formula(5) is transformed as follows:

$$
M \ddot{X}+C \dot{X}+K X=\left(C_{a e}+C_{\mathrm{Re}}\right) \dot{X}+K_{a e} X
$$

After the transfer of Formula(6), Formula(7) can be obtained as follows:

$$
M \ddot{X}+\left(C-C_{a e}-C_{\mathrm{Re}}\right) \dot{X}+\left(K-K_{a e}\right) X=0
$$

This is the flutter equation of the wind-rain-bridge coupled system. Due to the fact that the response of wind-induced vibration on the bridge structures is mainly composed of several order low-frequency vibration modes, some low-order vibration modes, such as $[\Phi]_{N \times m}$, can be selected from the natural vibration modes to analyze the characteristic value of flutter and calculate the critical wind speed of flutter.

The mass, stiffness and damping of the structural system can be simulated by inputting symmetric or asymmetric mass, stiffness and damping matrix in the general finite element software. Therefore, flutter analysis under the combined effect of wind and rain is carried out by using general finite element software in this paper, and rainfall damping, aerodynamic stiffness and aerodynamic damping elements are generated in the finite element model for corresponding simulation.

The matrixes of mass, stiffness and damping are respectively set in the simulation. Three elements are added at each node of the main beam, including aerodynamic stiffness element, rainfall damping element and aerodynamic damping element, as shown in Fig.2, and one node of the element is the main beam node I or node $\mathrm{J}$, and the other is fixed at any length.

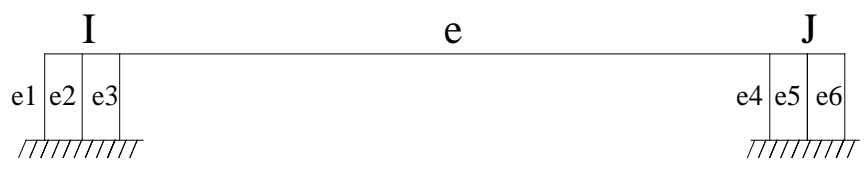

Fig.2 Simulation graph of aerodynamic self-excited force and rainfall damping of structural unit

The corresponding matrixes are shown as follows [15]:

$$
\begin{array}{r}
\left\{\begin{array}{l}
K^{e 1}=K_{a e}^{e-1}+K_{a e}^{e} \\
K^{e 4}=K_{a e}^{e}+K_{a e}^{e+1}
\end{array}\right. \\
\left\{\begin{array}{l}
C^{e 2}=C_{a e}^{e-1}+C_{a e}^{e} \\
C^{e 5}=C_{a e}^{e}+C_{a e}^{e+1}
\end{array}\right. \\
\left\{\begin{array}{l}
C^{e 3}=C_{r e}^{e-1}+C_{r e}^{e} \\
C^{e 6}=C_{r e}^{e}+C_{r e}^{e+1}
\end{array}\right.
\end{array}
$$

The overall matrix of the structure is generated by reorganizing the above matrix of each structural element, and a large number of low-order vibration modes are selected from the structural modal, so that the mass participation coefficient can reach more than 95\%. Based on the above method, the critical wind speed of flutter under the combined effect of wind and rain can be calculated by iterating the eigenvalue.

\section{Flutter analysis of long-span suspension bridge under wind and rain excitation}

\subsection{Engineering background}

The flutter analysis of long-span suspension bridge under wind and rain excitation is conducted based on a large span suspension bridge in a mountainous area in this paper, and the main bridge is a single span double-hinged steel truss suspension bridge. The main span is $420 \mathrm{~m}$, and the stiffening girder is $13.3 \mathrm{~m}$ wide and $3.6 \mathrm{~m}$ high, the height of main cable is $43.75 \mathrm{~m}$ and rise-span ratio is 1/9.6. The elevation of the bridge is shown in Fig. 3. 


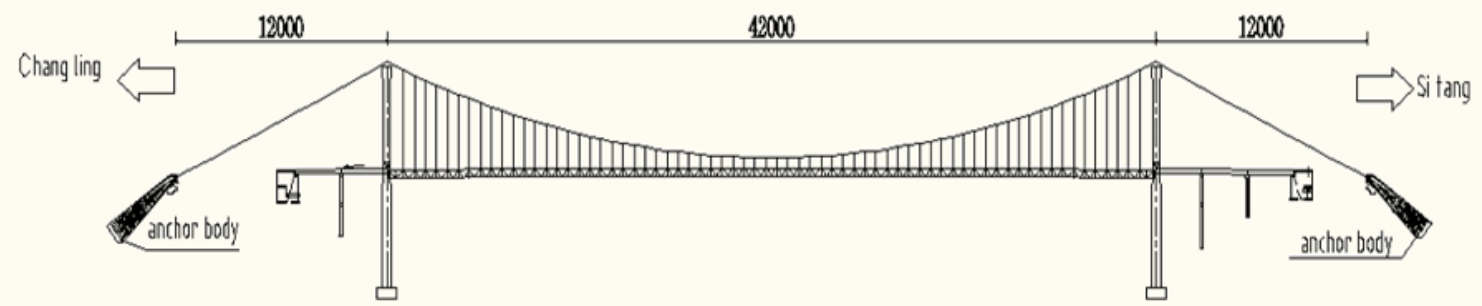

Fig.3 The elevation of a long-span suspension bridge (unit: $\mathrm{cm}$ )

\subsection{Results of suspension bridge flutter analysis}

The spatial finite element model of long-span suspension bridge is established in the general finite element software, in which the suspender and main cable are bar elements subjected to tension and the bridge tower and

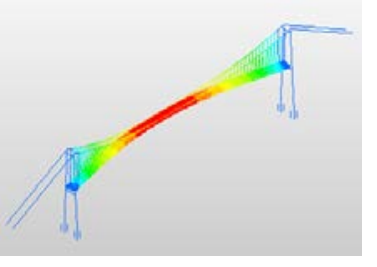

1order symmetric

transverse bending

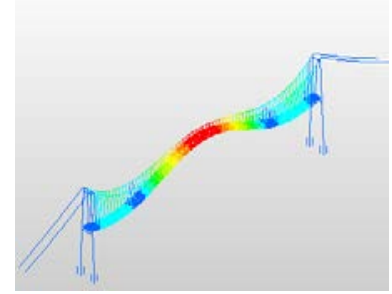

4 order symmetric

vertical bending

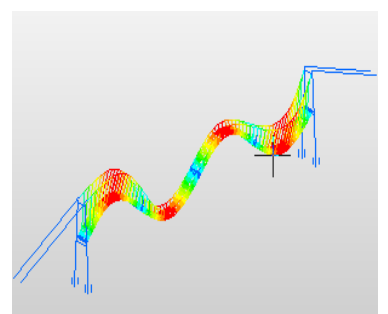

7 order antisymmetric vertical bending

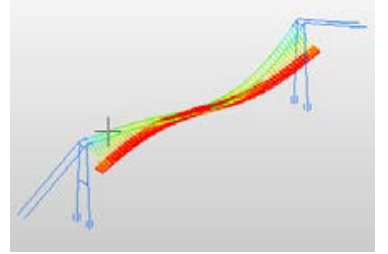

2 order antisymmetric

vertical bending

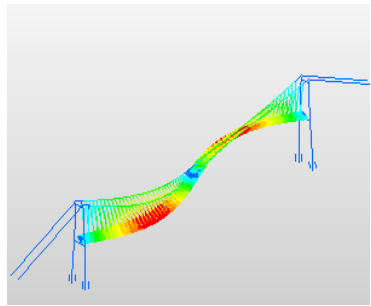

5 order antisymmetric

transverse bending

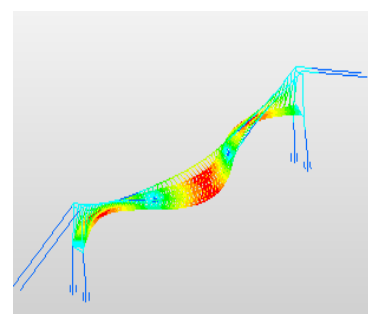

8 order symmetric torsion stiffening girder are spatial beam elements. The first 12 order torsion, transverse bending and vertical bending fundamental frequencies are obtained through modal analysis of the structure in the general finite element software, as shown in Fig.4, and the results are shown in Tab.1.

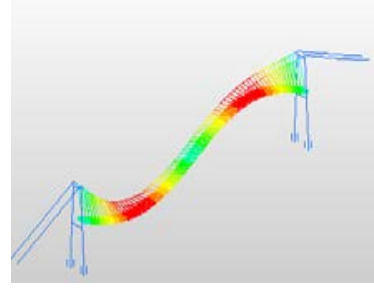

3 order antisymmetric vertical bending

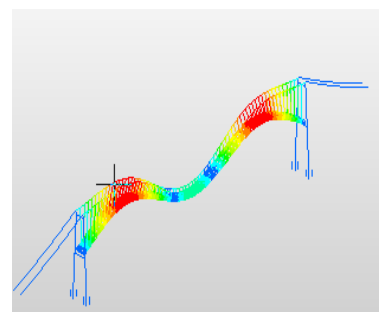

6 order symmetric vertical bending

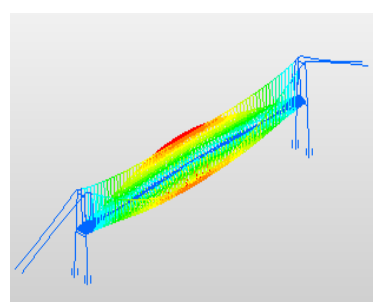

9 order symmetric torsion 


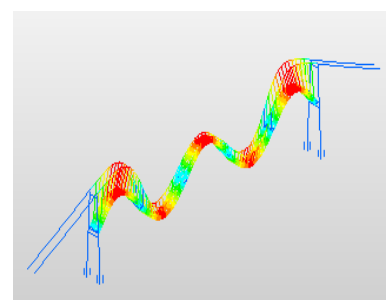

10 order antisymmetric vertical bending

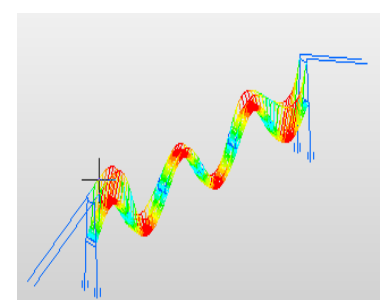

11 order antisymmetric vertical bending

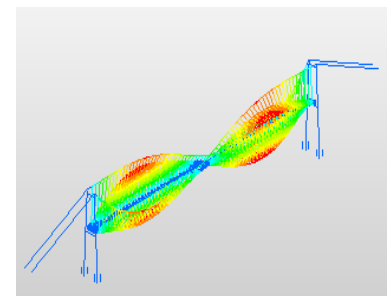

12 order antisymmetric torsion

Fig.4 The first twelve order fundamental frequencies of the suspension bridge

Table 1. Results of natural frequency on Structure

\begin{tabular}{|c|c|c|c|c|c|}
\hline Modal numbers & Frequency $(\mathrm{Hz})$ & Mode shapes & Modal numbers & Frequency $(\mathrm{Hz})$ & Mode shapes \\
\hline 1 & 0.1278 & $\begin{array}{l}\text { Symmetric } \\
\text { transverse } \\
\text { bending }\end{array}$ & 7 & 0.5781 & $\begin{array}{l}\text { Antisymmetric } \\
\text { vertical bending }\end{array}$ \\
\hline 2 & 0.1585 & $\begin{array}{l}\text { Antisymmetric } \\
\text { vertical bending }\end{array}$ & 8 & 0.7212 & $\begin{array}{c}\text { Symmetric } \\
\text { torsion }\end{array}$ \\
\hline 3 & 0.2504 & $\begin{array}{l}\text { Antisymmetric } \\
\text { vertical bending }\end{array}$ & 9 & 0.8006 & $\begin{array}{c}\text { Symmetric } \\
\text { torsion }\end{array}$ \\
\hline 4 & 0.32506 & $\begin{array}{c}\text { Symmetric } \\
\text { vertical bending }\end{array}$ & 10 & 0.8068 & $\begin{array}{l}\text { Antisymmetric } \\
\text { vertical bending }\end{array}$ \\
\hline 5 & 0.3598 & $\begin{array}{c}\text { Antisymmetric } \\
\text { transverse } \\
\text { bending }\end{array}$ & 11 & 1.0649 & $\begin{array}{l}\text { Antisymmetric } \\
\text { vertical bending }\end{array}$ \\
\hline 6 & 0.4376 & $\begin{array}{c}\text { Symmetric } \\
\text { vertical bending }\end{array}$ & 12 & 1.1063 & $\begin{array}{c}\text { Antisymmetric } \\
\text { torsion }\end{array}$ \\
\hline
\end{tabular}

It can be seen from the natural frequency of the structure in the dynamic characteristics, the structure of the long-span suspension bridge tends to be gentle, and its first-order transverse bending frequency is only $0.1278 \mathrm{~Hz}$. Based on the results of dynamic characteristics analysis, the mass participation coefficient has reached $96 \%$ in the first 12 order modal, therefore, the first 12 order modal are selected to analyze the critical wind speed of flutter under the combined effect of wind and rain.

The classification of rainfall used in this paper is shown in Tab.2. Based on the above method, the rainfall damping matrix of the stiffening girder element and the structure as a whole can be obtained through the rainfall velocity and rainfall intensity.

Table 2. The classification of rainfall used in this paper

\begin{tabular}{cccccccc}
\hline & Light & Moderate & Heavy & & Heavy & Heavy & Heavy \\
Classification & rain & rain & rain & Rainstorm & $\begin{array}{c}\text { rainstorm } \\
\text { (Light) }\end{array}$ & $\begin{array}{c}\text { rainstorm } \\
\text { (Moderate) }\end{array}$ & (Severe) \\
\hline $\begin{array}{c}\text { rainfall } \\
\text { intensity }\left(\mathrm{mm}^{*} \mathrm{~h}^{-}\right.\end{array}$ & 2.5 & 8 & 16 & 32 & 64 & 100 & 200 \\
1
\end{tabular}

Therefore, different elements are used to simulate rainfall damping, aerodynamic stiffness and aerodynamic damping, meanwhile, the analysis method of complex modal characteristic values is adopted to obtain the critical flutter wind speed of the structure under the consideration of wind only and the combined action of wind and rain, the results are shown in Tab.3 
Table 3. Results of flutter analysis under wind and wind-rain action

\begin{tabular}{ccccccccc}
\hline \multirow{2}{*}{$\begin{array}{c}\text { Types of } \\
\text { load }\end{array}$} & Wind & \multicolumn{7}{c}{ Wind - Rainfall } \\
\cline { 3 - 8 } & & $\begin{array}{c}\text { Light } \\
\text { rain }\end{array}$ & $\begin{array}{c}\text { Moderat } \\
\text { e rain }\end{array}$ & $\begin{array}{c}\text { Heavy } \\
\text { rain }\end{array}$ & Rainstorm & \multicolumn{3}{c}{ Heavy rainstorm } \\
\cline { 7 - 9 } $\begin{array}{c}\text { Critical } \\
\text { wind speed } \\
\text { of flutter }\end{array}$ & 89.56 & 89.77 & 90.03 & 90.2 & 90.77 & 91.56 & 92.39 & 94.40 \\
\hline Increment & - & $0.23 \%$ & $0.53 \%$ & $0.72 \%$ & $1.35 \%$ & $2.23 \%$ & $3.16 \%$ & $5.54 \%$ \\
\hline
\end{tabular}

Based on the analysis results in table 3 , it can be concluded that the critical wind speed of bridge flutter has changed and accordingly increased due to the existence of rainfall damping. Because the mass of raindrops is too light and the final velocity of raindrops in the falling process is low, the critical wind speed of flutter increased by only $5.54 \%$ in the case of heavy rainstorm. Therefore, when the rainfall intensity is general, the influence of rainfall on the critical wind speed of flutter can be ignored.

\section{Conclusions}

Strong convective weather such as strong monsoon usually accompanies rainfall, considering the influence of rainfall factors on bridge flutter, the flutter analysis method of long-span suspension bridge under the combined effect of wind and rain is improved in this paper, meanwhile, a long-span suspension bridge in a mountainous area of Hubei China was taken as the object for analysis, and the conclusions are as follows:

(1)Based on the main characteristics of rainfall, the impact of rainfall on the stiffening girder is analyzed, the damping effect of rainfall is derived and the unit damping matrix form of rainfall is proposed.

(2)The flutter motion equation of the wind-rain-bridge coupling system is derived. At the same time, the simulation of rainfall damping, aerodynamic damping and aerodynamic stiffness is carried out by using the general finite element software, and the finite element analysis method for critical wind speed of structural flutter considering the influence of rainfall is improved.

(3)The influence of rainfall on the critical wind speed of flutter is analyzed with a long span suspension bridge in a mountainous area of Hubei China as an object. The critical wind speed of bridge flutter has changed and accordingly increased due to the existence of rainfall damping, at the same time, due to the smaller inertia and mass of raindrops, even in the case of heavy rainstorm, the growth rate of critical wind speed of flutter is only $5.54 \%$. Therefore, it can be derived that the influence of rainfall on the critical wind speed of flutter can be ignored when the rainfall intensity is general.

\section{References}

1. XIN Dabo, LI Hui, OU Jinping, WANG Liang, CHEN Dongying. Experimental study on flutter stability of a long-span bridge subject to wind-rain actions[J]. Science China(Technological Sciences), 2013, 56(08): 2089-2098.

2. Wang Kai, Liao Haili, Li Mingshui. Study on flutter performance of long-span steel girder suspension bridges based on wind tunnel tests [J]. Journal of Vibration and Shock,2015,34(15):175-180+194.

3. Editorial Department of China Journal of Highway and Transport. Review on China's Bridge Engineering Research:2014 [J]. China Journal of Highway and Transport, 2014, 27(5):162-166.

4. Zhu Zhiwen, Gu Ming. A CFD-AM-CSD method on rapid prediction of the flutter critical wind speed of long-span bridges [J]. China Civil Engineering Journal, 2014, 46(7):88-96.

5. Lei Xu. Chen Zhengqing. Experiment on Vortex Vibration of Bridge Main Girder's Section Model Under Coupling Effect of Wind and Rain [J]. Journal of Architecture and Civil Engineering, 2018, 35 (3):54-62. 
6. Wang Liang. Wind-Rain-Induced Static and Dynamic Characteristics of Long-Span Bridge Decks [D]. Harbin Institute of Technology, 2011.

7. ZHAO Lin, GE Yao Jun, WU Zhanke, XU Linshan. Theoretic and testing investigation of wind -rain coupling loads on bridges and structures[J]. Journal of Vibration Engineering, 2014, 27(4):507-517

8. Fu Xing. Dynamic response and collapse analyses of transmission tower-line system subjected to wind and rain loads[D]. Dalian University of Technology, 2016.

9. CAO Y H, WU Z, XU Z L, et al. Effects of Rainfall on Aircraft Aerodynamics[J].Progress in Aerospace Sciences,2014,71:85-127.

10. DONG Guochao, ZHANG Jianren. Numerical Simulation of Wind-rain Coupling Effect on Typical Bridge Section Based on Lagrangian System[J]. Journal of Hunan University (Natural Sciences), 2017, 44(9):26-32.
11. Gao Q, Hui D, Deng Z, et al. Three-field coupling analysis for large-scale wind turbine with wind-rain-structure[J]. Journal of Central South University, 2016.

12. Masaru Abuku, Hans Janssen, Jean Poesen, Staf Roels. Impact, absorption and evaporation of raindrops on building facades. Building and Environment, 2009, 44: 113 124.

13. Gong Li. Erosion calculation of raindrops' kinetic energy of loess plateau's rainfall[J]. Journal of Lanzhou Jiaotong University(Natural Sciences), 2005, 24(4): 43-45.

14. CHEN Zhengqing. Wind-Induced Vibration, Stability and Control of Engineering Structures [M].China Science Publishing\&Media Ltd, 2013.

15. HUANG Wenfeng, ZOU Kongqing, SUN Jianpeng, WANG Meiqin. Buffeting response analysis of the suspension bridge in time domain [J]. Journal of Xi'an University of Architecture \& Technology (Natural Science Edition), 2015, 47(3):371-375. 